\title{
CONSCIÊNCIA REFLEXIVA, TEMPO PRESENTE, CIDADE FUTURA: SOBRE $A$ ROSA DO POVO, DE CARLOS DRUMMOND DE ANDRADE*
}

http://dx.doi.org/10.11606/issn.2237-1184.v0i34p134-146

Edu Teruki Otsuka ${ }^{I}$

RESUMO

Tomando como ponto de partida alguns núcleos temáticos identificados pela crítica na obra drummondiana, busca-se discutir o entrelaçamento dos temas do indivíduo e do tempo histórico, visando a apreender a configuração da subjetividade em poemas de A rosa do povo. Assim, o anseio de autoaniquilamento do indivíduo burguês será entendido em sua conexão com a crítica do presente e a expectativa de um futuro redimido, observando-se a posição de classe do sujeito, bem como o caráter histórico e os limites dessa conjunção. No primeiro Drummond domina a tonalidade irônica e humorística, de modo que o sujeito se desdobra e se hipertrofia para consolar as dores de seu eu apequenado, ao passo que, aqui, o consolo ao indivíduo enredado nos impasses políticos do presente parece surgir da promessa iminente de um mundo emancipado. No entanto, a obra subsequente de Drummond mostrará os limites da expectativa futura figurada em A rosa do povo, que não tardaria a defrontar sua frustração histórica.

\section{PALAVRAS-CHAVE:}

Carlos Drummond de Andrade; A rosa do povo; Autoconsciência crítica; Tempo histórico.

\footnotetext{
* Uma versão prévia deste texto foi apresentada no "Simpósio Internacional 70 anos de A rosa do povo", realizado na Biblioteca Brasiliana Guita e José Mindlin, USP, São Paulo, em 04 e 05 de agosto de 2015.

I Universidade de São Paulo, São Paulo, São Paulo, Brasil.
} 
ABSTRACT

Taking as a starting point some thematic elements identified by critics in the work of Drummond, this paper aims to discuss the conjunction of motifs concerning the individual and those related to the historical time, in order to discern the particular configuration of the poetic subject in poems of A rosa do povo. Thus, the desire for self-annihilation of the bourgeois individual will be read in its connection to the criticism of the present time and the hope for a redeemed future, taking into account the poet's class position, as well as the historical character and the limits of this conjunction. In the early Drummond the ironic and humorous mood dominates so that the poet unfolds and expands his subjectivity to comfort the pains of his diminished self, whereas here the individual caught in the present time's political deadlock seems to find comfort in the imminent promise of an emancipated society. However, Drummond's subsequent work would reveal the limits of the future expectation depicted in A rosa do povo, which would soon face a historical downfall.

\section{KEYWORDS}

Carlos Drummond de Andrade; A rosa do povo; critical selfconsciousness; historical time.

\section{A}

de Andrade, observa Antonio Candido que tanto sua prosa quanto sua poesia são atravessadas por uma "linha interna de severa autocrítica e infinita capacidade de emoção" (CANDIDO, 2002, p. 199). De fato, hoje é amplamente reconhecido que a atitude de Drummond diante dos impasses da subjetividade e das opressões do mundo, bem como do lugar social da poesia, é um dos núcleos geradores de sua obra. Essa atitude se manifesta na desconfiança permanente em relação à legitimidade e à eficácia do fazer poético, mas é antes de tudo resultado dos movimentos de uma "subjetividade tirânica" que, nas palavras de Antonio Candido, conduz à "autonegação pelo sentimento de culpa" (CANDIDO, 1970, p. 96).

A postura de autoconsciência crítica havia sido expressa diretamente por Drummond no prefácio a Confissões de Minas, escrito, como ele mesmo diz, "em agosto de 1943, depois da batalha de Stalingrado e da queda de Mussolini". Nesse prefácio, Drummond reconhecia que ao livro faltava "o tempo, com suas definições"; em sua avaliação, parecia estar ausente daquelas páginas as questões candentes do período, marcado pela ascensão do fascismo, o conflito político-ideológico e o andamento ainda incerto da Segunda Guerra Mundial: “As páginas foram-se escrevendo mais para contar ou consolar o indivíduo das Minas Gerais, e dizem bem 
pouco das relações desse indivíduo com o formidável período histórico em que lhe é dado viver." (ANDRADE, 2011, p. 13). Sem renegar a postura de aparente alheamento assumida nos textos do livro e afirmando uma ética da escrita em que sobressai a responsabilidade social do escritor, Drummond sugeria, ao final do prefácio, que não se encontrava mais no mesmo lugar em que estava quando escreveu os textos reunidos no volume, e que agora ele caminhava rumo a outras possibilidades: "Não estou pois dentro deste livro de retalhos, e sim fora dele. Mas sinto que foi um caminho pelo qual cheguei a uma excelente cidade, de ruas largas e populosas." (Observe-se desde já a referência à cidade como imagem utópica, a qual reencontraremos em alguns poemas de $A$ rosa do povo.) E conclui: "Ele [o livro] abriu minhas gavetas secretas. Libertou-me de alguns fantasmas particulares. Agiu. Hoje não escreveria quase nada do que aí se contém, mas por isso mesmo a sensação de desprendimento e liberdade é maior. Vamos andando." (ANDRADE, 2011, p. 14). Assim Drummond termina o prefácio, afirmando que segue adiante no novo caminho descoberto, agora mais balizado pelas coordenadas históricas do presente.

Essas observações de Drummond podem servir como introdução ao assunto deste artigo, pois assinalam, a seu modo, uma mudança de atitude por meio da qual a abertura do indivíduo para o mundo social viria a atingir um ponto máximo na obra poética subsequente. Essa mudança corresponde ao enfrentamento, em novo patamar, de questões fundamentais que estavam presentes desde o início de sua obra. A disposição mais abertamente participativa, que vinha se anunciando, como é sabido, desde Sentimento do mundo (1940), encontrou expressão vigorosa em alguns poemas de $A$ rosa do povo (1945), mas sem que se anulasse por completo a orientação predominante nos livros anteriores. ${ }^{1}$

Para caracterizar brevemente a atitude que prevalece nos primeiros livros, remeto ao ensaio "Poesia e humor" de Ivone Daré Rabello (2002). Não cabendo retomar aqui todos os passos do argumento, digamos que o estudo identifica o modo específico pelo qual Drummond enfrenta, na sociedade brasileira, a condição histórica da lírica moderna, decorrente do processo que afastou o poeta da praça pública, para sua maldição e seu comprazimento, tornando problemático o lugar social da poesia. Nas obras iniciais de Drummond, predomina a postura irônica em que o eu se desdobra e brinca com o próprio sofrimento; é assim que, contra a atrofia histórica do sujeito, que o condena à impotência, a subjetividade reage hipertrofiando sua potência no jogo com as palavras, por via do humour. $\mathrm{O}$

\footnotetext{
${ }^{1} \mathrm{O}$ entrelaçamento dos temas políticos e sociais na poética engajada e dos temas da memória e da reflexão subjetiva no lirismo individual foi assinalado e investigado em profundidade por Iumna Maria Simon (2015).
}

136 d Dummond em Foco: Múltiplas Leituras: Na Sala de Aula 
desdobramento irônico, sem anular o pathos da comoção, permite a visão distanciada e reflexiva que faz ver, junto ao sujeito esmagado pelo mundo, a realidade amesquinhada a que ele é confinado, e podemos observar aí o sentido crítico que decorre da ironia.

A atitude irônica e humorística prevalece nas obras iniciais, mas é justamente em um dos poemas de $A$ rosa do povo que Ivone Rabello encontra uma de suas manifestações mais depuradas. Em "Consolo na praia", o humour corresponde ao momento em que, segundo Freud, o superego, habitualmente associado ao "senhor severo" e por vezes tirânico, assume uma feição "maternal" e conforta o eu, dando-lhe forças para que não se curve às mazelas do mundo. Assim, as duas últimas estrofes: "A injustiça não se resolve./ À sombra do mundo errado/ murmuraste um protesto tímido./ Mas virão outros.// Tudo somado, devias/ precipitar-te - de vez - nas águas./ Estás nu na areia, no vento.../ Dorme, meu filho." $2 \mathrm{O}$ sofrimento, inicialmente apenas individual (com a perda da infância e da mocidade, dos amores, do melhor amigo), mostrase em sua dimensão coletiva, social, e aponta a expectativa da perseverança futura no embate, enquanto, no fim, o humour se converte em acalanto que conforta o sujeito fragilizado com o convite ao sono.

O que se vê aí é o sujeito que reconhece a própria fragilidade no conflito com o mundo errado e, desdobrando-se para aliviar o sentimento esmagador de impotência, abre-se para o movimento em direção ao outro, irmanando-se a outros homens e mulheres diante do sofrimento coletivo numa situação histórica que promove a iniquidade. Um movimento análogo está presente em "Uma hora e mais outra":

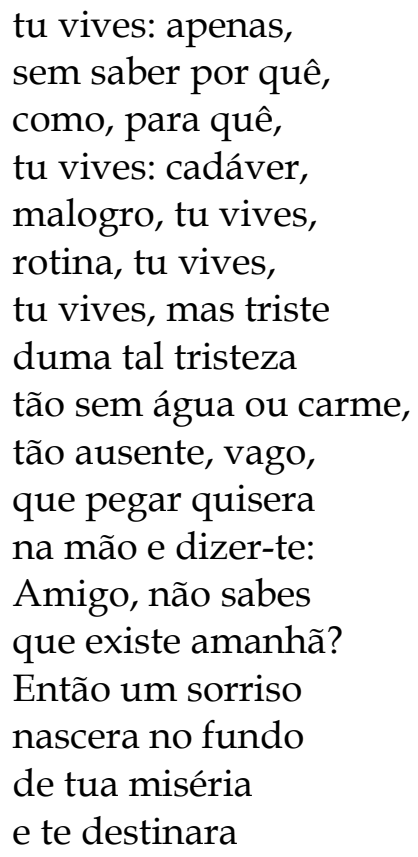

2 Todas as citações de poemas provêm de Carlos Drummond de Andrade (2012). 


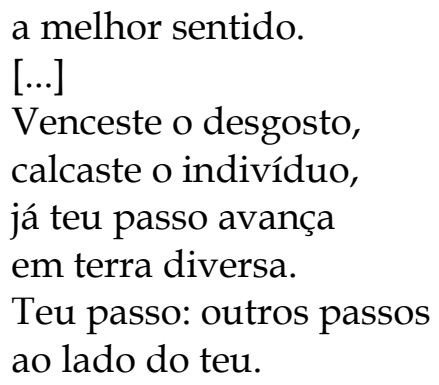

Assim, o movimento da subjetividade que nos interessa aqui parte da percepção da própria fragilidade e, deixando para trás o isolamento melancólico, se volta para o outro e para o mundo social, passando a reconhecer na dor individual o fundo comum do sofrimento coletivo decorrente do curso aparentemente implacável da história. A partir desse reconhecimento seria possível escapar ao círculo fechado do isolamento e alcançar "terra diversa", conjugando os próprios passos aos de outros e formando uma marcha coletiva para explorar novos caminhos. Para que tal percurso se efetive, porém, o sujeito deve antes enfrentar sua consciência culposa, o que supõe, de início, um momento de reflexão autopunitiva que, em suas manifestações exacerbadas, ganha figuração em imagens pungentes de dissolução de si mesmo.

Em A rosa do povo, são frequentes as imagens de mutilação, autoaniquilamento e morte (cf. CANDIDO, 1970, p. 101). A pré-ciência do desastre no avião ("Morte no avião"), a antecipação ou o ensaio da própria morte no sono ("Uma hora e mais outra", "Desfile"), o senso do perecimento da matéria golpeada pela mão pesada do tempo ("Versos à boca da noite") e o desejo consciente de aniquilamento, seja na versão cômico-fantástica de "O mito", em que o sujeito quer "das mortes a mais hedionda", seja na versão desencantada de "Anoitecer", em que "o corpo não pede sono,/ depois de tanto rodar;/ pede paz - morte - mergulho/ no poço mais ermo e quedo" - são exemplos da imagética centrada na dissolução do indivíduo. Uma dissolução que é simultaneamente temida e ansiada, na medida em que parece articular-se a um desejo de renovação, como indicam os versos de "Vida menor": "a fuga de si mesmo/ [...]/ Não a morte, contudo.// Mas a vida [...]/ vida mínima, essencial".

Nas imagens de mutilação e morte se manifesta o sentimento de culpa, em parte decorrente do desajustamento do sujeito gauche em relação ao curso do mundo, em parte intensificado pela autoconsciência em relação aos limites de seu próprio lugar social (cf. CANDIDO, 1970; CAMILO, 2003). Preso à sua classe, assim como ao passado brasileiro a que se liga pela linhagem familiar e ao presente da cidade moderna em que, como outros, é "um homem/ na engrenagem" ("Morte no avião"), o sujeito defronta o apequenamento de seu poder de ação, o medo que isola e paralisa, e a incomunicabilidade, entendidos como resultado histórico que 
ele busca recusar, ao mesmo tempo em que padece das limitações que lhe são impingidas pela marcha do mundo capitalista: "Assim nos criam burgueses" ("O medo").

Por isso mesmo, as imagens de aniquilamento, longe de representarem rendição ou entrega à derrota, podem ser entendidas como expressões extremadas de um desejo de libertação - um desejo que, no entanto, só encontra figuração poética em imagens de anulação completa do eu. Assim, em outro momento, a dissolução do indivíduo se apresenta como via de acesso ao contato efetivo com o outro e à solidariedade. É o que se vê em "Movimento da espada", que se inicia com os seguintes versos:

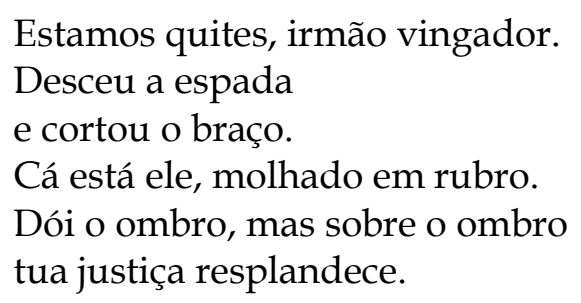

Nesse poema, a amputação promovida pelo "irmão vingador" parece ser um ato de agressividade, mas é reconhecido como um gesto amoroso ("Já podes sorrir, tua boca/ moldar-se em beijo de amor"; "Tua lâmina corta, mas é doce"), que o desvencilha daquilo que o limita: "O que perdi se multiplica". Mutilado, "puro e imparcial como um cadáver", o sujeito se torna "carga jogada às ondas" enquanto o sol continua a brilhar por cima de tudo ("sobre minha cova, como brilha o sol!") e ele pode afinal receber a dádiva do sol que o irmão vingador lhe oferece, "na aparência roubando-o". O gesto fraternal, que parecia privar o sujeito (de movimento, de vida, de luz), desprende-o de si mesmo e permite que ele se aproprie do que lhe é precioso. Assim, a vingança destruidora se revela como uma espécie de redenção.

$$
* * *
$$

O desejo de autoanulação do indivíduo encontra ressonância nas imagens do mundo presente que atravessam $A$ rosa do povo, imagens em que também a alienação coletiva é figurada como mutilação: "Este é o tempo de divisas,/ tempo de gente cortada./ De mãos viajando sem braços,/ obscenos gestos avulsos." ("Nosso tempo"). O tempo histórico, aludido nas referências à cidade moderna, é apresentado sob a aparência de fragmentação e desumanização. Assim, em "Anoitecer", a cidade é tomada por ruídos sinistros de "buzinas,/ sirenes roucas, apitos/ aflitos, pungentes, trágicos,/ uivando escuro segredo", enquanto se veem 
"multidões compactas/ escorrendo exaustas/ como espesso óleo/ que impregna o lajedo". Em outros poemas, igualmente surgem imagens do presente sombrio, tomado por doenças, degradação e injustiça: "enfastiado/ assistes ao dia/ perseverar no câncer,/ no pó, no costume,/ no mal dividido/ trabalho de muitos" ("Uma hora e mais outra"); ou "Chegando ao limite/ dos tempos atuais,/ eis-nos interditos/ enquanto prosperam/ os jardins da gripe,/ os bondes do tédio,/ as lojas do pranto." ("Nos áureos tempos").

Na conhecida parte V de "Nosso tempo", apresenta-se a cena opressiva da vida moderna, com os negócios que se alastram invisíveis e dominam a alma; os jornais que falsificam as palavras; os cartórios que glorificam a propriedade privada; os bancos que trituram e os usurários que exploram; a má poesia, o mau romance; e os homens fracos que transigem e "se entregam à proteção do basilisco". Essa V parte do poema se inicia com o sujeito observando "a hora formidável do almoço/ na cidade" (formidável, etimologicamente, é o "que provoca temor"):

As bocas sugam um rio de carne, legumes e tortas vitaminosas.

Salta depressa do mar a bandeja de peixes argênteos!

Os subterrâneos da fome choram caldo de sopa, olhos líquidos de cão através do vidro devoram teu osso.

Come, braço mecânico, alimenta-te, mão de papel [...]

Depois, terminado o expediente, chega a "hora espandongada da volta", em que o sujeito observa a movimentação das pessoas na cidade, captada na sucessão indiferenciada de pessoas e coisas:

\footnotetext{
Homem depois de homem, mulher, criança, homem, roupa, cigarro, chapéu, roupa, roupa, roupa, homem, homem, mulher, homem, mulher, roupa, homem imaginam esperar qualquer coisa, e se quedam mudos, escoam-se passo a passo, sentam-se, últimos servos do negócio, imaginam voltar para casa, já noite, entre muros apagados, numa suposta cidade, imaginam.
}

O isolamento de cada pessoa no meio da multidão e a alienação geral simultaneamente apontam para uma aspiração a algo diferente, já que todos "imaginam esperar qualquer coisa". Mesmo num momento de máxima dispersão, se reconhece no conjunto dos habitantes isolados a latência de um senso difuso de espera: homens e mulheres imaginam, talvez, uma verdadeira cidade, em contraste com a "suposta cidade" em que dominam os gestos mecanizados, o espetáculo nauseante do almoço (também presente em "Uma hora e mais outra": "não a da comida/ hora mais grotesca/ em que dente de ouro/ mastiga pedaços/ de besta caçada") 
e o triste escoar das pessoas para o refúgio doméstico (como nos já citados versos de "Anoitecer": "multidões compactas/ escorrendo exaustas"). No início do poema, também o sujeito, observando o mundo, espera por algo melhor: "Calo-me, espero, decifro./ As coisas talvez melhorem." (Algo semelhante se encontra em "A flor e a náusea", como se observa nesta enumeração que termina com "espera", cujo sentido ambivalente parece introduzir uma brecha no conjunto sombrio: "O tempo é ainda de fezes, maus poemas, alucinações e espera.")

Essa aspiração difusa, que é do sujeito e também de todos os outros, no entanto, encontra apenas compensações, bálsamos fugazes (a leitura, o jogo, o passeio na praia, o sexo, o sono), que propiciam o esquecimento momentâneo do incessante girar em falso da Grande Máquina, mas que, integrados ao ritmo do todo, repõem a lógica sufocante do mundo caduco (para lembrar os termos da extraordinária "Elegia 1938", de Sentimento do mundo). Assim também em "Uma hora e mais outra": "não a do cinema/ hora vagabunda/ onde se compensa,/ rosa em tecnicólor/ a falta de amor,/ a falta de amor, A FALTA DE AMOR". Tais compensações, em "A flor e a náusea", são sentidas pelo sujeito como outros tantos motivos de culpa e incluem o fazer artístico, inescapavelmente entrelaçado ao privilégio social: "Crimes da terra, como perdoá-los?/ Tomei parte em muitos, outros escondi./ Alguns achei belos, foram publicados./ Crimes suaves, que ajudam a viver."

De qualquer modo, importa salientar a confluência entre a dimensão individual da autocrítica impiedosa e a apreensão, não menos impiedosa, do presente enquanto estado de coisas a recusar. Ao mesmo tempo, o sujeito reconhece, no interior mesmo da mais densa alienação, a latência da aspiração utópica, a espera por outras possibilidades de vida, embora essa esperança só apareça em sua versão rebaixada, como espera pela " pequena hora noturna de compensação" ("Nosso tempo"), que não atende aos verdadeiros anseios humanos. Nas fraquezas e dificuldades do sujeito individual ressoam os problemas e constrangimentos coletivos: assim, em "A flor e a náusea", "[o] tempo pobre, o poeta pobre/ fundem-se no mesmo impasse", impasse cuja resolução decerto só poderia advir por meio da ruptura com o atual curso da história.

Ainda em "A flor e a náusea", o desejo de autoanulação, que pode assumir feição violenta, se identifica com a negação do presente inaceitável, e o gesto destruidor se iguala ao desejo de transformação: "Pôr fogo em tudo, inclusive em mim./ Ao menino de 1918 chamavam anarquista./ Porém meu ódio é o melhor de mim./ Com ele me salvo/ e dou a poucos uma esperança mínima."

Ainda que mínima, a esperança de vida plena se apresenta e é figurada em outros poemas como uma cidade ansiada, "a cidade dos 
homens completos" ("Nosso tempo"). De início, a cidade desejada é uma aspiração imprecisa: "Como fazer uma cidade? Com que elementos tecêla?", pergunta-se o sujeito em "América". No quadro histórico em que os poemas de $A$ rosa do povo foram escritos, a expectativa difusa de renovação pareceu encontrar uma possibilidade de concretização efetiva nos desdobramentos da Guerra então em curso, mas cujo desfecho ainda permanecia indeterminado. Assim, a cidade que inicialmente é apenas um anseio sem forma por um momento se converte em "cidade prevista", deduzida por antecipação, como imagem futura "[d]esse mundo/ que não verei, mas virá/ um dia, dentro em mil anos,/ talvez mais... [...]/ Uma cidade sem portas,/ de casas sem armadilha".

O ponto alto dessa expectativa está em "Carta a Stalingrado", em que o poeta saúda a cidade que, lutando, detém o avanço das forças reacionárias. Stalingrado, embora destroçada, é apresentada como anúncio de transformação e de construção de um mundo novo. A vitória, "que por enquanto é apenas uma fumaça subindo do Volga", ao final do poema é afirmada com convicção: "Em teu chão calcinado onde apodrecem cadáveres,/ a grande Cidade de amanhã erguerá a sua Ordem." No desenvolvimento do poema, é significativo que a cidade arrasada seja figurada como um corpo humano despedaçado, do qual o sujeito se aproxima afetivamente, num movimento de identificação com a cidade geograficamente distante mas presente na imaginação do poeta (cf. MOURA, 2012, p. 168-9):

A tamanha distância procuro, indago, cheiro destroços apalpo as formas desmanteladas de teu corpo, [sangrentos, caminho solitariamente em tuas ruas onde há mãos soltas e [relógios partidos, sinto-te como uma criatura humana, e que és tu, Stalingrado, [senão isto?

Desse modo, a atitude do sujeito indicada antes, que figura o desejo de autotransformação por meio das imagens de mutilação e morte, encontra aqui certa correlação com o modo pelo qual a esperança de transformação do mundo é simbolizada nas imagens do corpo desmembrado da Stalingrado arrasada na batalha, mas da qual surgirá a "cidade de amanhã". Atente-se também para a imagem dos "relógios partidos", que Murilo Marcondes de Moura interpreta como um signo da interrupção do tempo, ou seja, algo que indica uma ruptura da marcha corrente da história e anuncia o possível início de outra organização social (cf. MOURA, 2012, p. 170). 
Ainda que de modo diverso, a interrupção do fluxo temporal é precisamente o que a flor informe de "A flor e a náusea" parece realizar, concretizando a negação do presente, ao furar "o asfalto, o tédio, o nojo e o ódio". A flor, que ainda é uma "forma indecisa" ("Sua cor não se percebe./ Suas pétalas não se abrem"), simboliza o surgimento de algo ainda desconhecido e inteiramente novo ("Seu nome não está nos livros"), que irrompe na rua de maneira inesperada, ilude a vigilância repressora da polícia, e quer fazer cessar toda a agitada movimentação urbana de "bondes, ônibus, rio de aço do tráfego", signos da sociedade impulsionada pelo progresso. ${ }^{3}$ Assim, pelo menos para o sujeito que observa a cena, a irrupção imprevista da flor parece exigir a suspensão do curso destrutivo da história, e o sujeito a acompanha nessa ruptura do fluxo temporal: "Sento-me no chão da capital do país às cinco horas da tarde/ e lentamente passo a mão nessa forma insegura." Assim, no centro do turbilhão da grande cidade, o sujeito interrompe a andança e senta-se no meio da rua para realizar demoradamente o gesto de aproximação à novidade que brota ainda hesitante e instável, como a verificar a "realidade" da flor que nasceu.

A possibilidade de realização da expectativa não se dá sem o movimento de aproximação ao outro, que em $A$ rosa do povo também se manifesta como aspiração ao canto coletivo, embora esse canto não chegue propriamente a se concretizar como solução formal (cf. SIMON, 1983; 1978). Os dois poemas que fecham o livro, homenageando Mário de Andrade e Charles Chaplin ("Mário de Andrade desce aos infernos" e "Canto ao homem do povo Charlie Chaplin"), decerto remetem a soluções artísticas ao problema da superação da distância do artista em relação aos homens comuns. Em Mário de Andrade, temos a incorporação da experiência social multiforme do povo por meio do mergulho "nos mais diversos brasis"; em Chaplin, temos a despersonalização pela habilidade mimética que possibilita ao artista ser muitos sem deixar de ser ele mesmo, alcançando assim a experiência que diz respeito a todos:

[...] os abandonados da justiça, os simples de coração, os párias, os falidos, os mutilados, os deficientes, os recalcados, os oprimidos, os solitários, os indecisos, os líricos, os [cismarentos, os irresponsáveis, os pueris, os cariciosos, os loucos e os [patéticos.

\footnotetext{
3 A crítica ao progresso que se depreende no poema poderia, talvez, ser proveitosamente discutida a partir das concepções de Adorno (1995).
}

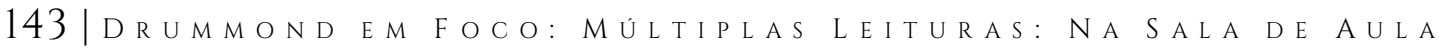


Mas, para Drummond, as atitudes de Mário de Andrade e de Chaplin parecem permanecer como soluções que não estão ao seu alcance, justamente devido à severa autoconsciência reflexiva, que atua em muito de sua melhor poesia. É desta forma que, em sua obra, o desejo de reconstrução da humanidade, pelo resgate do impulso utópico mesmo nas condições de sufocamento por uma alienação aparentemente sem brechas, é tensionado pelo travo amargo da percepção de sua impossibilidade imediata ("A rosa do povo despetala-se"), como uma consciência dolorosa de que o mundo poderia ser diferente e, no entanto, continua a existir tal como é. 4

Nesse sentido, cumpre assinalar por fim que a disposição participante - impulsionada pela expectativa de um futuro emancipado e favorecida pelas circunstâncias do momento em que o rumo da sociedade parecia estar em aberto - também não tardaria a defrontar uma enorme frustração histórica. Nos Novos poemas, que se seguiram a $A$ rosa do povo, não se encontra - e como poderia? - a exaltação de uma nova sociedade iminente, nem qualquer satisfação com os resultados do término da Guerra, quando o mundo se apresentava, na aparência, totalmente "pacificado". Pelo contrário, os poemas que tratam diretamente de temas políticos se voltam para persistência da ditadura franquista na Espanha ("Notícias de Espanha") e para aquilo que, no passado não-redimido, permanece como a aspiração irrealizada de uma humanidade comum, simbolizada na morte de García Lorca ("A Federico García Lorca"). Mais que isso, o momento do imediato pós-guerra conduziu antes a um ponto máximo de negatividade na obra de Drummond: como é dito em "Composição", o que restou da demolição mais completa de tudo é somente o "barro, sem esperança de escultura".

\section{Referências bibliográficas}

ADORnO, Theodor W. "Progresso". In: Palavras e sinais: modelos críticos 2. Trad. Maria Helena Ruschel. Petrópolis: Vozes, 1995, p. 37-61.

ANDRADE, Carlos Drummond de. Confissões de Minas. São Paulo: Cosac Naify, 2011.

ANDRADE, Carlos Drummond de. Poesia 1930-62: de Alguma poesia a Lição de coisas. Edição crítica por Júlio Castañon Guimarães. São Paulo: Cosac Naify, 2012.

\footnotetext{
${ }^{4}$ Neste passo, aproveito livremente observações de Sigfried Kracauer sobre Chaplin (apud HANSEN, 2004, p. 418-9).
}

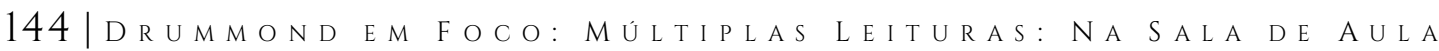


CAMILO, Vagner. "O fazendeiro do ar e o legado da culpa”. In: PENJON, Jacqueline; PASTA JÚNIOR, José Antonio (orgs.). Littérature et modernisation au Brésil. Paris: Presses Sorbonne Nouvelle, 2003, p. 205-227.

CANDIDO, Antonio. "Inquietudes na poesia de Drummond". In: Vários escritos. São Paulo: Duas Cidades, 1970, p. 93-122.

CANDIDO, Antonio. "Notas de crítica literária - Confissões de Minas". In: Textos de intervenção. Organização de Vinicius Dantas. São Paulo: 34: Duas Cidades, 2002, p. 198-204.

HANSEN, Miriam B. “Estados Unidos, Paris, Alpes: Kracauer (e Benjamin) sobre o cinema e a modernidade". In: CHARNEY, Leo; SCHWARTZ, Vanessa R. (orgs.). O cinema e a invenção da vida moderna. $2^{\mathrm{a}}$ ed. Trad. Regina Thompson. São Paulo: Cosac Naify, 2004, p. 405-450.

MOURA, Murilo Marcondes de. "Poesia política". Cadernos de literatura brasileira. Rio de Janeiro, n. 27, p. 154-176, outubro de 2012.

RABEllo, Ivone Daré. "Poesia e humor". In: DAMÁSIO, Reynaldo (org.). Drummond revisitado. São Paulo: Unimarco, 2002, p. 107-122.

SIMON, Iumna Maria. Drummond: uma poética do risco. São Paulo: Ática, 1978.

SIMON, Iumna Maria. "Na praça de convites". In: SCHWARZ, Roberto (org.). Os pobres na literatura brasileira. São Paulo: Brasiliense, 1983, p. 140-148.

SIMON, Iumna Maria. "O mundo em chamas e o país inconcluso". Novos Estudos CEBRAP. São Paulo, n. 103, p. 169-191, 2015. DOI: https:/ / doi.org/10.25091/s0101-3300201500030009 
Edu Teruki Otsuka é professor doutor do Departamento de Teoria Literária e Literatura Comparada da Universidade de São Paulo. É autor de marcas da catástrofe: experiência urbana e indústria cultural em Rubem Fonseca, João Gilberto Noll e Chico Buarque (2001) e de Era no tempo do rei: atualidades das Memórias de um sargento de milícias (2016). Contato: eduotsuka@usp.br

ORCiD: https://orcid.org/0000-0002-5283-6251 